\title{
Neurology and the new health care policies
}

\author{
Rosati G. \\ Istituto di Clinica Neurologica dell'Università di Sassari, Italy
}

\begin{abstract}
The Author discusses some aspects of the Health Care systems in developed countries, and analyzes the reasons for the failure of recent reform programs to provide good quality service at a reasonable price. While not condemning business-style management completely, the Author points out how, in the neurological field too, under the control of physicians, biomedical research and innovation with inter-departmental collaboration can be managed according to specific aims, so as to prevent much costly and wasteful diagnostic and therapeutic practice, thus improving service quality while reducing hospital running costs.
\end{abstract}

Key Words: Health care system reform - Health care policies - Managed care - Disease management - Cost containment - Health care quality - Biomedical innovation - Biomedical research - Neurological patient load Neurology.

The governments of nearly all the developed countries, whatever the type of health care system in use, are trying to change their health policies, in order to face a number of very grave problems. In the first instance, expenses are growing faster than available economic resources; secondly, it it becoming more and more difficult for the population to avail itself of health care services; thirdly, there is a growing dissatisfaction about the quality of health care, in relation to the cost sustained by the population.

The growth of health care expenditure has been particularly high in the United States, rising from $\$ 250$ billion in 1980 ( $9.2 \%$ of the GDP), to $\$ 903$ billion in 1993 ( $14.4 \%$ of the GDP). The most alarming consequence of this phenomenon has been a progressive erosion of middle-class health care coverage to such an extent that, in 1993, the number of American citizens completely unprotected by the health care system had reached 37 million [27]. In the United States, therefore, the problem concerns the health care coverage of the population and the cost of services.

In other countries where there are public health care systems, like the U.K. and Italy, the factors underlying this growing cost are also becoming overwhelming. The present policy of cost-containment in practice in the U.K. (and to some extent also in Italy), is founded on the conviction that the introduction of free-market competition, produces greater efficiency in services, and a drop in management costs. This has had other drawbacks, such as longer waiting-lists and penny-saving in medical services, with more and more dissatisfied patients. The revolution in progress in Italy is similar to that in the U.K., with a clear division between acquirer (Azienda USL) and service suppliers (Aziende Ospedaliere, Servizi a

Invited Lecture to the XXIX Congress of the Italian Neurological Society. Rome, November 25-29, 1995.
Gestione Diretta, Servizi Privati) and a fee-for-service type of payment. This form of payment requires by law a maximum tariff per service, which can only be undersold to stimulate competition.

The limits of a policy of mere cost-control, as is being applied in the developed countries, are brought to the surface by concomitant factors like demographic ageing and technological innovation. It is now clear that it is not enough to aim at greater efficiency to reform health care systems, and that the decision to be taken is whether the performance available to the public should be based on cost-benefit or cost-effectiveness, and if it is good enough and fast enough.

For some time a new policy, aimed at associating cost problems, performance quality and health-coverage together, has been in practice in the United States. This policy is based on the transformation of the "fee for service" system into a system of capitation, called "managed-care" $[1,4,5,9,13,27,28]$, and is the central point of the Clinton Reform. Although the reform has for the moment been suspended, "managed-care" is spreading to form what could be termed a series of private health care systems, which are able to keep costs down, while at the same time improving service quality. This entails an evaluation of diagnostic, therapeutic and preventive strategies, to determine which can modify the natural history of a disease effectively, and at a cost which is acceptable to the community.

The essential concept of "managed care" is disease management, that is, a process of improvement in diagnostic and therapeutic procedures for specific diseases, starting with the most prevalent or most disabling. The aim of this is to produce guide-lines with which to manage the various diseases properly, without wasting resources. The idea is difficult to put into practice due to a serious lack of reliable outcome parameters in the various clinical and health strategies currently used. Outcome evaluation is 
difficult and complicated, requiring long follow-up studies on large populations, and the centres where cost-effectiveness parameters have been established for each speciality are very few. One of the few diseases for which the literature provides enough data to lay down valid guide-lines is cardiopathic ischemia. In the field of neurology, data of this kind are practically nonexistent, even if stroke is one of the pathologies receiving the most attention from "managed-care" [8].

In other words the main tool of "managed-care" is not only cost-control, as it would be for a bureaucratic approach, but also research on outcome seen as a strategic factor, aimed at better understanding of which procedure is best, and for who [3]. Taken from this point of view, "managed-care" is being proposed as an effective means of fighting poor quality service in those countries with a public health care system [23].

All these points raise an important issue on the role of biomedical research and innovation in the reform of health care systems. Many of the problems affecting health care are due to underestimation of the importance of research and health care quality which, by working together, play a vital role in improving the way public health care services function. Because these factors are so little understood, many refuse to believe that an improvement in health care quality, driven by evaluation studies on the various clinical and health procedures and by a proper use of biomedical innovation, can also lead to cost reduction.

If one considers what has been published over the last four years, in an important American publication, it is possible to see that, on a total of 370 articles, $80 \%$ spoke about growing costs, $15 \%$ about the lack of health coverage in a certain proportion of the population, and only $4 \%$ considered the issue of health care quality and biomedical innovation. It is only through research that the effects of future decisions can be understood (especially on the more vulnerable areas), and action taken to apply correction and improvement properly, cost-control included, according to the aims chosen. Even if it may seem wrong to use the methods of company production in a system as complex as health care, it should not be forgotten that, in many sectors of production, the introduction of the concept of overall quality has halved the expenses of many companies, which used to spend as much as $25-30 \%$ of their budgets to correct mistakes in production management.

Research is also the only means by which health care workers can see the value of what they are doing properly, and so clear away preconceptions that risk to impoverish both the present, and future generations' health care services.

One particularly harmful preconception, which persists in many people responsible for decisions on health care policies, is the conviction that funding and biomedical innovation are directly proportional. This is due to the use of biassed incentives (the so-called "cost-plus reimbursement" for infrastructure and equipment, the "fee-forservice" system of payment, and commercial use of biomedical research and innovation, etc.), all of which encourage the use of biomedical innovation in a very different direction to that of improving health care service quality, while keeping costs down. It is for precisely this reason that very little attention has so far been paid to the benefits of research and innovation, even though there are examples to show that, when properly applied, research is capable of providing successful therapies for serious diseases, together with considerable cost reduction [22]. It is therefore clear that biomedical research is a strategic factor in the success of health care policies, and should be encouraged. As a corollary of this, biomedical research imperatively needs to be supported, in order to ensure a constant flow of effective therapies and clinical procedures with which to treat the most frequent diseases, and those which are most disabling, as well as the new forms of pathology which have developed, or will develop as a function of demographic ageing. Pathologies of this kind are very frequent in the field of neurology.

Hospital service is a crucial element in the reform of health care systems. Hospital expenses have risen very fast, absorbing ever more of the health care budgets. In Italy, for example. hospital expenditure in the years 1982 to 1992 has risen by $360 \%$, which is more than $55 \%$ of the entire Italian health care budget. The result is that, in most of the developed countries, the expense-cuts so far put into practice have hit hospital funding, without giving any consideration to the quality of health care. This is presently happening in Italy, where the major hospitals are being transformed into free-market focused business concerns, organized in such a way as to reflect the traditional concept of bureaucracy, which is generally defined as "a hierarchy of roles and inter-relations, regulated by an authority, and having fixed areas of competence".

Studies in the field of organization sciences have long since demonstrated that a model of this type, which follows the logic of decisions taken at high levels, and which is based on the conviction that there is only one "best" way to run a business in spite of differing aims, is not suitable for managing complex systems $[17,18,21$, 25].

There is no doubt that the running of a hospital is complex, since its goal is to mediate between health care policy (social aims), and the way in which service is offered (human behaviour). Out of this arise a number of problems which are beyond the scope of government control. There is friction between the people involved in decision-taking: it is hopeless to try to evaluate the efficiency of a unit in terms of the number of patients admitted, or the number of check-ups or operations carried out (only the degree to which patient health improves is worth using as a yardstick for efficiency); there are certain factors which bear heavily on running expenses, such as interaction between the operative units and subunits of a hospital (patient wards, operating theatres, diagnostic departments, equipment, etc.), which the spread of technology and increasing specialization are making ever more complicated; there is the fact that physicians, who are responsible for many decisions in matters of 
spending, with considerable freedom to act as they see fit in the clinical sphere (and properly so), do not brook bureaucratic interference in their work lightly.

It is therefore essential, when considering the aims and characteristics of a hospital, to use a form of management which is capable, at the same time, of choosing the most cost-effective strategies, of stopping wasteful methods, and of improving the quality of the care.

In a similar manner it is necessary to organize the work in such a way as to solve (a) the problems between direct health care and supporting systems; (b) any friction between department heads and various categories of personnel; (c) the particularly troublesome marriage between health care practitioners and health care administration and running in the traditional form of hospital organization. This last named problem may well get worse, if the business-style type of organization proposed in Italy is put into practice.

There exist several studies $[6,7,15,20]$ which show that the improvement of health care cost-effectiveness requires an organization based on the direct participation of health care staff in the running of hospitals and, in particular, greater management and decision-making responsabilities at every level, from the choice of aims to be reached, to a sensible distribution of available resources; from budget management, to the assessment of results in terms of cost-benefit; from a proper use of guide-lines, to applied biomedical research. Many do not understand, or pretend not to understand, that expenditure depends essentially on the decisions taken by doctors, and that it is possible to avoid the risks inherent to purely bureaucratic control only by their close involvement in the running of health care units.

Based on the conviction that efficient hospital running depends principally on a real co-involvement of health care practitioners in administrative and management functions [28], the centralization of authority must be prevented (contrary to what is happening in Italy), and decision-making responsibility placed firmly in the hands of health care departments, which of course requires that a reasonable incentive be given to physicians, and other health care workers who take a part in the running of hospitals. It is important that each department be involved in the choice of general and specific aims, as well as in discussions on budgeting; that they be responsible for staff training, for checking that the approved guidelines are properly applied, and for the quality of the health care they are providing. If a department is involved in multi-centre outcome research, it should also be responsible for setting down a number of guide-lines. A department run on these lines would also be the most suitable for directing interaction between the various clinical activities, as well as smoothing away harmful friction among members of the professional staff.

What has so far been said against short-sighted, cost-cutting policies is an issue open to discussion, but it should not be forgotten that, even if it proves possible to uphold the quality of health care, the future picture will be one of economic restrictions. In an editorial which was published in 1993 in Annals of Neurology [19], it was stat- ed that, because of economic and health changes in the developed countries, a reduction of services, restrictions in diagnosis and therapy, cost-cutting and the ever increasing use of cost-effectiveness criteria on the various clinical and health care procedures, will become a part of future medical practice. The article concluded by saying that, if neurologists are to survive, their work must prove itself to be cost-effective, and that they must provide outcome studies on the methods used, with emphasis on the most frequent and most costly diseases they have to treat, in order to convince the "primary care providers" to support them.

The challenge has to be faced. The number of cases requiring the services of neurologists is far higher than health "experts" are given to believe. Indeed, a study carried out by Kurtzke in the United States [11], based on the prevalence, incidence and average duration of 61 different kinds of neurological disorder (those listed by the ICD are about 500 ), calculated that $9.5 \%$ of the general population may require the services of a neurologist at any one time. Many of these potential users can be treated satisfactorily by general practitioners or other specialists, but over one quarter $(2.5 \%$ of the general population) requires the assistance of a neurologist.

A study carried out in Saskatchewan, Canada [16], showed that from 1983 to 1985 the average yearly percentage of the general population admitted to hospital for treatment of neurological disorders had been $1 \%$, with an everage of 9 days hospitalization. Applying these estimates to the situation in Italy (with due consideration for differences in the health care systems from country to country), the Italians who need the services of a neurologist are about $1,400,000(2.5 \%$ of the general population), while those who are actually admitted to hospital for strictly, or mainly, neurological disorders are 570,000 $(1 \%)$. Taking 9 days as an average period of hospitalization (in Italy this average period is considerably higher), a total of $5,130,000$ days is reached. Nearly 19,000 hospital beds a year would be needed to satisfy this demand, assuming a $75 \%$ user rate, which is more than $7 \%$ of the hospital bed pool available to the entire Italian health care system, as established by the present legislation ( 4.5 beds/ 1000 population). This works out at 0.33 beds per 1000 inhabitants, which is already twice the total number of beds available for neurology and neurosurgery, as defined by the regional health plans prior to the reform. It should be added that the patient-load on neurology is increasing with progressive population ageing, and that a great many neurological pathologies are chronic or disabling.

It is instructive to observe that, in the mid-70s, in a period governed by over-spending phobia, the United States (according to an NINCDS estimate) were spending nearly $\$ 20$ billion a year on neurological care [14], and that in the same period the NINCDS, and other federal or private agencies, were investing more than $\$ 200$ million a year on physiological and pathological research on the nervous system [26].

The issue of neurology organization within hospitals is very important, for obvious reasons. Since in Italy the 
number of beds available to neurologists is considerably lower than the potential demand, many of the patients who request admission for neurological complaints inevitably find themselves in non-neurologic wards. The neurologist sees the patient in haste, often without being able to consult with the doctor who is following the patient, and the result is frequently a series of costly and useless diagnostic tests (the fear of making mistakes is typical in young practitioners), which the neurologist very often doesn't see, since he is excluded from an overall clinical evaluation. In many cases it is held that imaging, or some other costly diagnostic procedure, will be enough to draw definite conclusions, and the neurologist is appealed to only when all else fails. The situation is aggravated by the fact that neurological patients are assigned to wards without any other selection criteria than bed availability. This is bad for the patients, who are subjected to a plethora of different approaches, and wasteful of resources. Indeed, an excessive reliance on modern techniques in the formulation of diagnoses is responsible for nearly half the recent tremendous rise in health care costs [10]. It is the consequence of a widespread unknowledge of the limits of technology, and over-specialization of young neurologists. The lack of training in more general fields (a characteristic of the younger generation of practitioners) is becoming serious, because it is the only means by which excessive or futile use of new diagnostic techniques can be prevented [12] The unity of internal medicine has been destroyed by the spread of sub-specializations, with such disastrous effects as to set off a process of self-criticism [2]. The field of neurology finds itself in the unenviable position of being the most vulnerable to cost-cutting policies because of the size of its patient-load (at least $15 \%$ of hospitalized cases require the services of neurology in some form or other, since there is practically no field of medicine from which neurology is excluded), and because of the expense of most of the diagnostic procedures currently used.

Neurologists must find a way to make epidemiological evidence convincing and, at the same time, reduce expenditure while preserving the quality of health care. In this context, guidelines with which to manage the various neurological disorders properly, and without waste, are urgently needed. The practice of directing neurolog- ical patients to non-neurological wards, with all the inefficiency it entails. must be stopped; all patients requiring neurological assistance should come under the responsibility of neurologists, from the first moment of their admission, to their discharge from the hospital.

I believe that the force of the department model described above lies in the fact that it represens the best solution to all these problems, if placed in the context of an organization which, by involving health staff and doctors in the management, is able to use cost as the function of a certain level of quality.

The creation of guidelines requires collaboration among all the neurological specialities, a great deal of research, and the setting up specialized departments of neurology for study on selected patient populations according to the specific study area (and not only direct patient care) of each single department.

The other aim, that of putting the neurologist in the condition of being able to provide all the co-ordinated attention a patient requires, could be reached by setting up neurological intensive-care units within internal medicine departments. This solution does not circumscribe neurologists' freedom of action but, on the contrary, encourages the transfer of the up-to-date knowledge which only specialists have, to other doctors belonging to the department. It will be clear that a number of issues dear to the heart of many neurologists have not been touched on, such as neurological rehabilitation, laboratories for clinical neurobiology, first-aid neurology and so on, but it should not be forgotten that Italy has embarked upon a long and complex renewal of its health care system. which cannot be either short, or painless.

The reform of a health care system is a complicated game to play, and an eye must be kept on cost of course, but if at the same time the quality of health care, public access to the service and biomedical innovations are ignored, the game will certainly be lost.

A great many of those who are responsible for taking decisions on health care believe that these problems are not inter-related, and that they can be solved one by one. It is we who must show them, in a way they can understand, that this is not so, and that it is only by an intelligent and constructive use of such inter-relations that health care reform will succeed in providing an efficient, high quality service, at a reasonable price.

Acknowledgment: I wish to express my most grateful thanks to my brother Gianfranco Rosati for his valuable and irreplaceable help. This paper would never have come out, if not for his knowledge on health organization matters.

\section{Sommario}

I tenfativi di rinnovamento dei sistemi sanitari vigenti nei vari paesi sviluppati hanno lo scopo di contenere l'enorme crescita della spesa sanitaria. Le politiche rivolte al mero contenimento della spesa rischiano tuttavia di influenzare negativamente la qualità dell'assistenza. Per rinnovare i sistemi sanitari non basta porsi l'obiettivo di una maggiore efficienza dei servizi, ma occorre stabilire se le prestazioni erogate sono valide in termini di rapporto costi-efficacia e se le prestazioni stesse sono erogate in modo tempestivo e qualitativamente adeguato. Per realizzare l'obiettivo di migliorare la qualità dell'assistenza riducendo gli sprechi, è necessario investire sulla ricerca biomedica promuovendo studi di outcome in grado di fornire linee guida affidabili e valutare in modo adeguato $i$ benefici connessi all'innovazione tecnologica, eliminando i fattori che favoriscono un uso distorto dell'innovazione stessa. Occorre altresi attivare forme organizative che prevedano un maggior input dei medici e degli altri addetti all'assistenza nel processo decisionale ai vari livelli. 


\section{References}

[1] Bowles R.L.: Managed Care: theoretical and practical. J-Health-Care-Poor-Underserved 5: 173-177, 1994.

[2] BRAUNwald E.: Subspecialists and internal medicine: A perspective. Ann. Intern. Med. 114: 76-78, 1991.

[3] BREDESEN P.: Public/private partnerships in managed care. J-Health-Care-Poor-Underserved 5: 185-19I, 1994.

[4] Ceslowrrz S.B.: Managed care: controlling costs and changing practice. Medsurg Nurs. 2: 359-366, 1993.

[5] CurRy R.H., RafFerty M.P., HuCKaby S.K. et al.: Public hospitals and managed care. J-Health-Care-PoorUnderserved 5: 33-46, 1994.

[6] DONABEDIAN A.: Models for organizing the delivery of personal health services and criteria for evaluating them. In: Zola I.K., McKinsly J.B. (Eds.), Organization Issues in the Delivery of Health Services. New York: Prodist, 1974.

[7] DREsNick S., ROTH W.I., LINN B.S. et al.: The physician's role in cost-containment problem. JAMA 241: 1606-1609, 1979.

[8] GoREL.IK P.B.: Stroke prevention. Arch. Neurol. 52: $347-$ $355,1995$.

[9] IGLEHART J.K.: The struggle between managed care and fee-for-service practice. N. Engl. J. Med. 331: 63-67, 1994.

[10] INSTITUTE OF MEDICINE: Assessing medical technologies. Washington, DC: National Academy Press, 1985.

[11] KURTZKE J.F.: The current neurologic burden of illness and injury in the United States. Neurology 32: 1207-1214, 1982.

[12] MENKEN M.: A social and epidemiologic approach to use of technology in neurologic practice. Neuroepidemiology, 11: 151-157, 1992.

[13] Miller R.H., LuFT H.S.: Managed care plan performance since 1980. A literature analysis. JAMA 271: 1512$1519,1994$.

[14] National Institute of Neurological and Communicative Disorders and Stroke: Neurological and Communicative Disorders. Estimated numbers and costs. Washington, DC: US Government Printing Office, 1976.

[15] NEUHAUSER D.: The relationship between administrative activities and hospital performance. Chicago: Center for Health Administration Studies, 1971.

[16] Rasput A.H.. UITTI R.J., RajPUT Alex H.: Neurological disorders and services in Saskatchewan. A report based on provincial health care records. Neuroepidemiology 7 : $145-151,1988$

[17] RHEE S.O.: Factors determining the quality of physician performance in patient care. Med. Care 14: 733-750. 1976.

[18] RHEE S.O.: Relative importance of physician's personal and social characteristics for quality of patient care. J. Hith. Soc. Behav. 18: 10-15, 1978.

[19] RINGEL S.P.: Can neurologists survive or thrive with health care reform? Ann. Neurol. 33: 441-444, 1993

[20] Roemer M.I., Friedman J.W.: Doctors in hospitals: medical staff organization and hospital performance. Baltimore: John Hopkins Press, 1971.

[21] ROSATI G., TARONI F.: Valutazione del prodotto e organizzazione dell'ospedale. Come (Periodico Dipartimento Sicurezza Sociale Regione Emilia-Romagna), Suppl. 3, pp. 29-34, 1986.

[22] ROSATI G.: Le relazioni tra spesa sanitaria, qualitò dell'assistenza e innovazione biomedica sul funzionamento dei sistemi sanitari. Parma, 1994 (comunicazione personale).

[23] SANDRICK K.: Out in front. Managed care helps push clinical guidelines forward. Hospitals, 67: 30-31, 1993.

[24] SOFFEL D., LUFT H.S.: Anatomy of health care reform proposals. West J. Med. 159: 494-500, 1993.

[25] STRASSER S.: The effective application of contingency theory in health setting: problems and recommended solutions. Health Care Manage Rev. 8: 15-23, 1983.

[26] TOWER D.B.: Neurological epidemiology: an introductory perspective. In: Schoenberg B.S. (ed.), Neurological Epidemiology: Principles and Clinical Applications. Advances in Neurology, vol. 19. New York: Raven Press, pp. $1-7,1978$.

[27] WeIL T.P.: President Clinton's managed competition proposal. J. Natl. Med. Assoc. 85: 257-263, 1993.

[28] WRIGHT S., WRIGHT A.: A cooperative organizational form for hospitals. Health Care Manage Rev. 9: 7-19. 1984.

Address reprint requests to: Prof. G. Rosati. Istituto di Clinica Neurologica dell'Università di Sassari, Viale San Pietro, 10, 07100 Sassari, Italy. 